\title{
Repair of the ruptured thoracic aorta using left ventriculo-aortic support
}

\author{
P. J . MOLLOY
}

Cardiac Surgical Unit, Royal Victoria Hospital, Belfast

Details of three cases of ruptured thoracic aorta are presented with reference to important diagnostic features, particularly hypertension, radiograph appearances and development of murmurs. An account of left ventriculo-aortic support for the distal circulation is given. This uses the ventricle as the pump, in circumstances where left atrio-femoral bypass may not be practicable, and is shown to be technically satisfactory and to provide adequate distal support.

In 1965 English described the use of left ventriculo-femonal bypass during resection of a coarctation complicated by an anomalous right subclavian artery arising below the coarctation. In this case left atrio-femoral bypass was not practicable as there was virtually no part of the left atrium accessible. No complication arose from the method used.

The purpose of this paper is to present three patients who suffered rupture of the thoracic aorta in road traffic accidents in whom repair was achieved using left ventriculo-aortic bypass to protect the spinal cord, kidneys, and lower half of the body. Such distal support is even more important than in coarctation, where there is usually an adequate collateral circulation which will protect these vital organs.

\section{CASE REPORTS}

CASE 1 J. B., aged 59 years, was hit by a car which lifted him on to the bumper, fracturing both tibias



FIG. 1. Case 1. Chest radiograph showing ruptured diaphragm and widened mediastinum. 
and fibulas, threw him across the bonnet and carried him along the road for 50 yards $(45 \mathrm{~m}$.). On admission he was concussed and unconscious, and had various lacerations and the fractures mentioned above. He was dyspnoeic and shocked. After resuscitation, a chest radiograph (Fig. 1) showed clear evidence of a ruptured diaphragm and widening of the mediastinum. The leg fractures were reduced and plastered under anaesthesia. Twenty-four hours later he was seen with a view to dealing with the ruptured diaphragm locally, but because of the suspicion of a ruptured aorta he was transferred to the Regional Cardio-thoracic Centre at Broadgreen Hospital. His condition on arrival was satisfactory, with a blood pressure of $150 / 90 \mathrm{~mm}$. Hg. His peripheral pulses were palpable in each arm and leg. $\mathrm{He}$ was mildly dyspnoeic.

Operation Preparations were made for left atriofemoral bypass, but on reflection this was thought impracticable because of the splinting and plaster immobilizing the legs, extending onto the abdomen.

The chest was explored through the left sixth rib bed. The pleural cavity contained $500 \mathrm{ml}$. of blood clot and the stomach and omentum, which had herniated through a paracrural tear in the diaphragm $4 \mathrm{~cm}$. lateral to the phrenic nerve. There was wide bruising of the mediastinum with a localized bulging haematoma at the ligamentum arteriosum region. The pericardium was free of blood or fluid, and there was no pulmonary injury.

The diaphragm was repaired first as it was thought that aortic repair might be difficult and if resuscitation problems arose the diaphragm tear might have to be abandoned. The abdominal contents were reduced through the tear after deflating the distended stomach through a peroral tube. The rupture in the diaphragm was repaired with nylon suture in two overlapping layers without tension. There was no evidence of injury to any abdominal viscus.

Before dissecting the para-aortic haematoma, through which aortic disruption could be felt on gentle palpation, left ventriculo-aortic bypass was instituted Through a stab wound in the left ventricular apex, protected by an 00 silk purse string, a 6-mm. caval cannula was introduced. This had been divided in two and the two halves were connected by a 6-mm. connector with a lateral Luer lock fitting for removing air from the circuit (Fig. 2). The distal end was trimmed to a point and introduced into the aorta at the level of the eighth thoracic vertebra. A purse string of 000 silk had previously been inserted and the introduction was done using a Beck clamp and a vertical incision in the aorta. Air was aspirated and the clamps were removed. Flow could be seen through the tubing. The patient was not heparinized.

The para-aortic pleura was opened above at the level of the left subclavian artery and below $5 \mathrm{~cm}$. below the level of the bulging haematoma, and

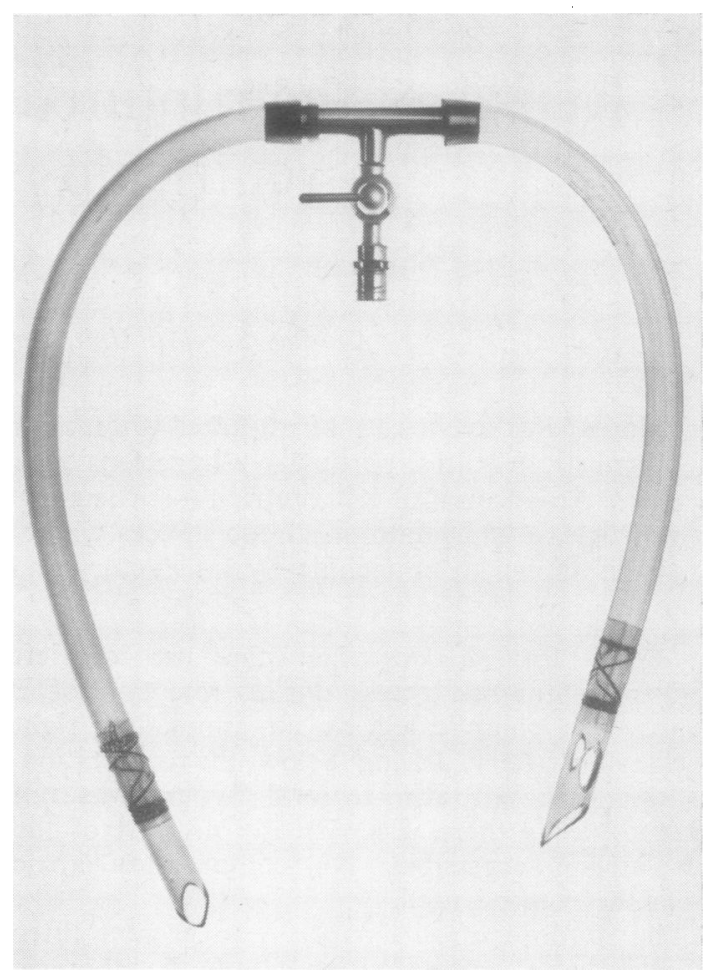

FIG. 2. Cannula used for left ventriculo-astic bypass. Note side arm in connection for removing air.

rubber slings were passed around the aorta, which was then clamped proximally and distally. Flow increased in the bypass tube and a good pressure was easily palpable in the distal aorta. Two intercostal 3 arteries required ligation. The pleural incision was extended over the haematoma to reveal a completely transected aorta. The entire circulation had been held on a bridge of adventitia only. The tear spiralled 윽 around the aorta, starting posteriorly at the liga- $\square$ mentum arteriosum and wound around anteriorly from right to left. This made direct suture impracticable. so the ends were trimmed and a $2-\mathrm{cm}$. length or of $2 \cdot 5-\mathrm{cm}$. woven Teflon was sutured end-to-end to $\mathrm{N}$ restore aortic continuity. On releasing the aortic N clamps there was free flow through the graft without leakage. The bypass was clamped and once a stable circulation was maintained each end was removed $\mathscr{C}$ and the incisions were closed. Distal perfusion was $\mathbb{D}$ easily palpable. The chest was closed with pleural $\stackrel{+}{+}$ drainage. His convalescence from this intervention $T$ was unremarkable. Urinary function was maintained and there was no evidence of neurological damage other than a right lateral popliteal nerve palsy noted at the time of the original reduction of the leg fractures. His only remaining disability two years later is the nerve palsy, which has largely recovered. 


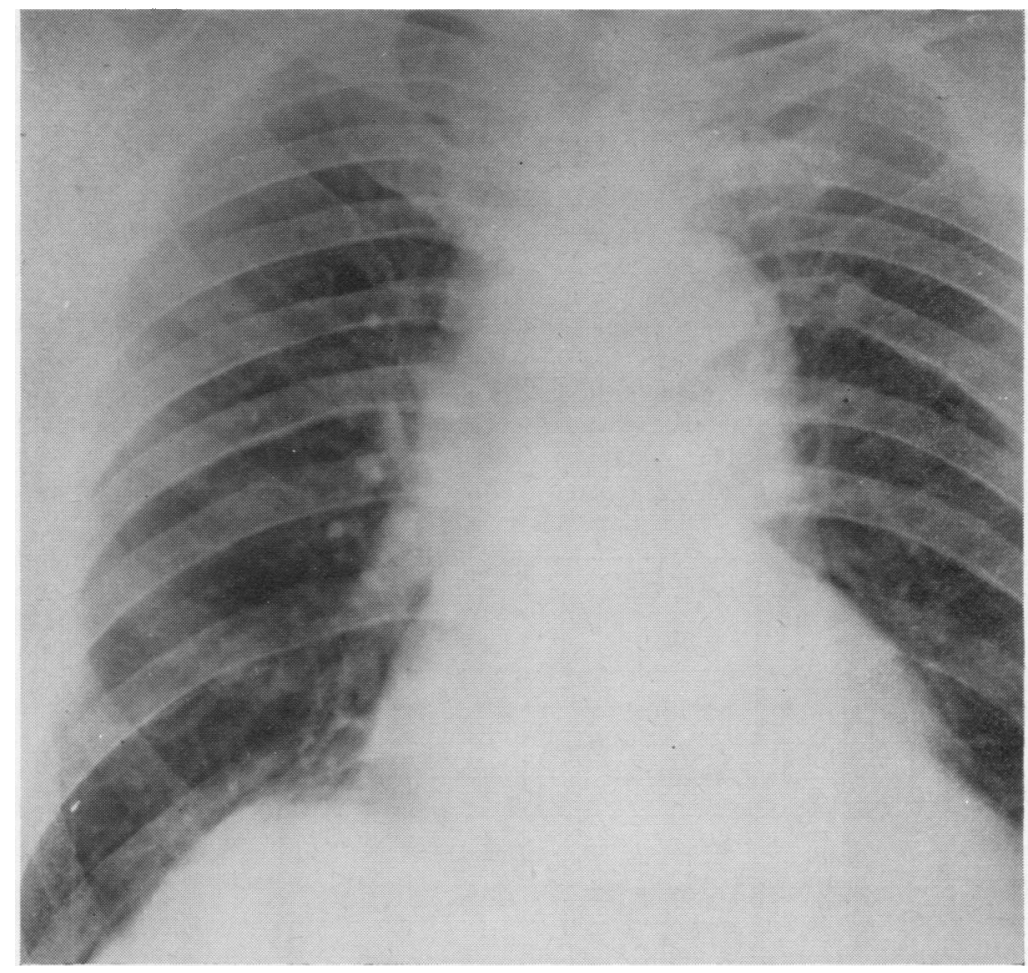

FIG. 3. Case 1. Chest radiograph two years after accident showing diaphragm level normal and slightly widened mediastinum.



FIG. 4. Case 2. Chest radiograph showing perihilar haematoma on right and wide mediastinum. 
A chest radiograph (Fig. 3) shows the mediastinum still widened, but there has been no increase in this in two films at a year's interval.

CASE 2 D. R., aged 27 years. was taken from a wrecked car which had crashed head first into a tree. He was jack-knifed over the steering wheel, unconscious and shocked. On admission to Sefton General Hospital, Liverpool, intra-abdominal haemorrhage, a ruptured diaphragm, and a dislocated hip were diagnosed. Through an abdominal incision a laceration in the liver was oversewn and the tear in the diaphragm was repaired from below. The hip was reduced. The left chest was drained by an intercostal tube. It was elected to ventilate this patient because of his head injury and the difficulty in maintaining adequate respiratory exchange. A chest radiograph (Fig. 4) showed a haematoma of the right perihilar region and middle lobe with widening of the mediastinum. His peripheral pulses had been easily palpable, but the femoral pulses did not feel of such high tension as the radial pulses. Blood pressure recordings showed a remarkable rise to $230 / 130$ $\mathrm{mm}$. $\mathrm{Hg}$ some five hours after the initial operation $\vec{\omega}$ (Fig. 5). The significance of this was not appreciated at the time. Seventy-two hours later, because of per- $\vec{x}$ sistent cyanosis on attempting to wean him from in the ventilator, he was seen by the author. The raised iv

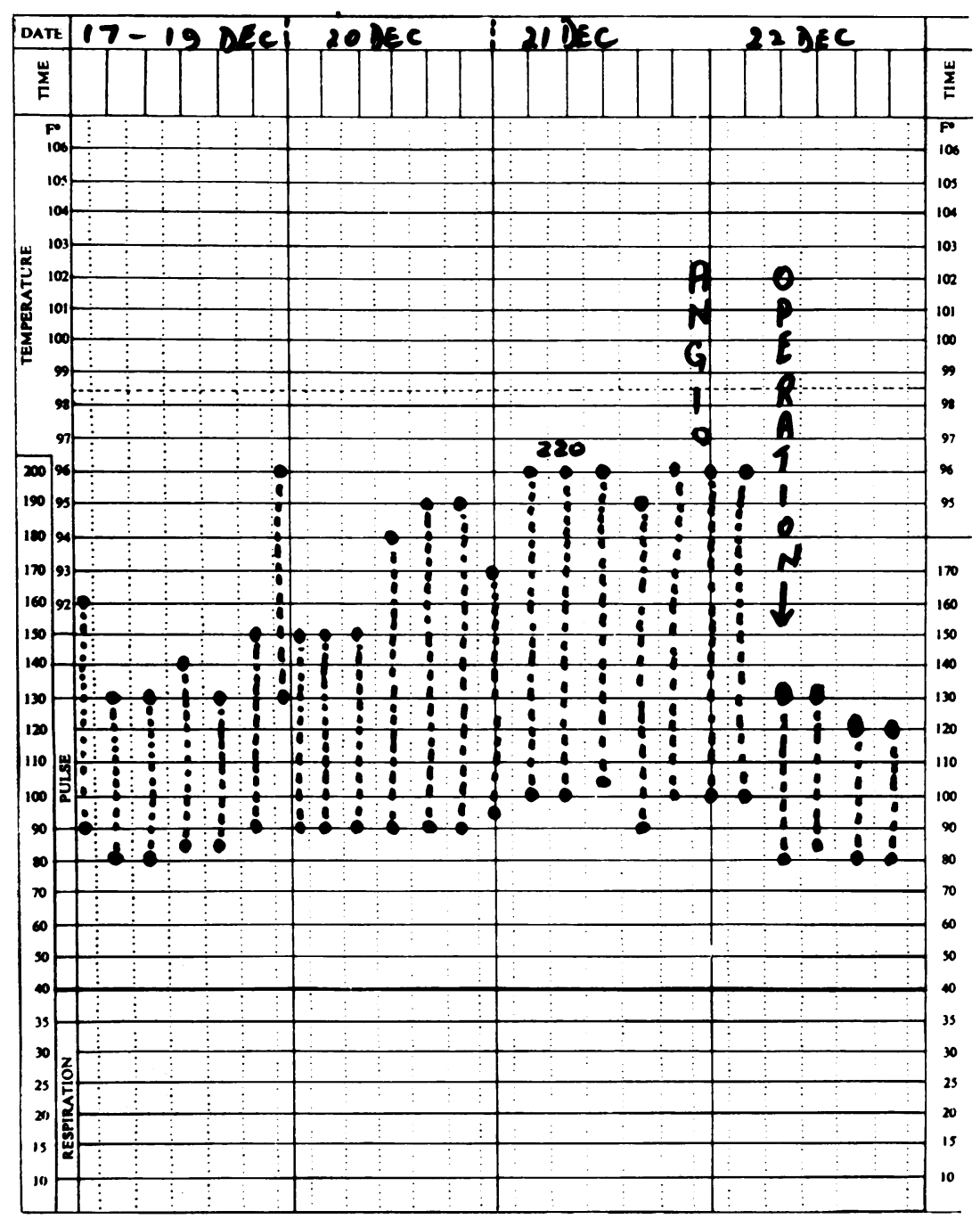

FIG. 5. Case 2. Blood pressure chart showing rise in blood pressure after initial laparotomy to hypertensive levels. Angio=date of performance of aortogram. 


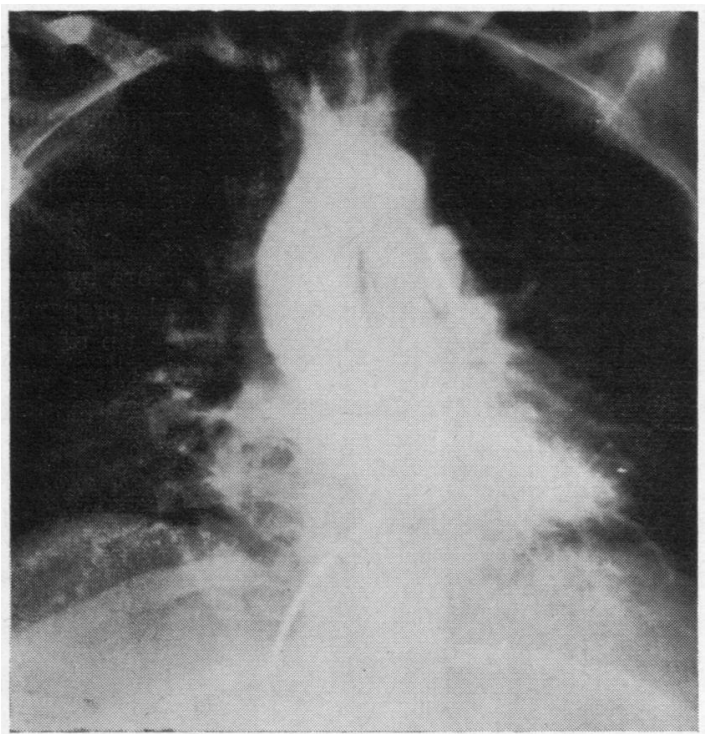

FIG. 6. Case 2. Prograde aortogram showing aortic rupture below left subclavian origin. Catheter is in pulmonary artery.

FIG. 7. Case 3. Admission radiograph showing fractured ribs and haemopneumothorax.

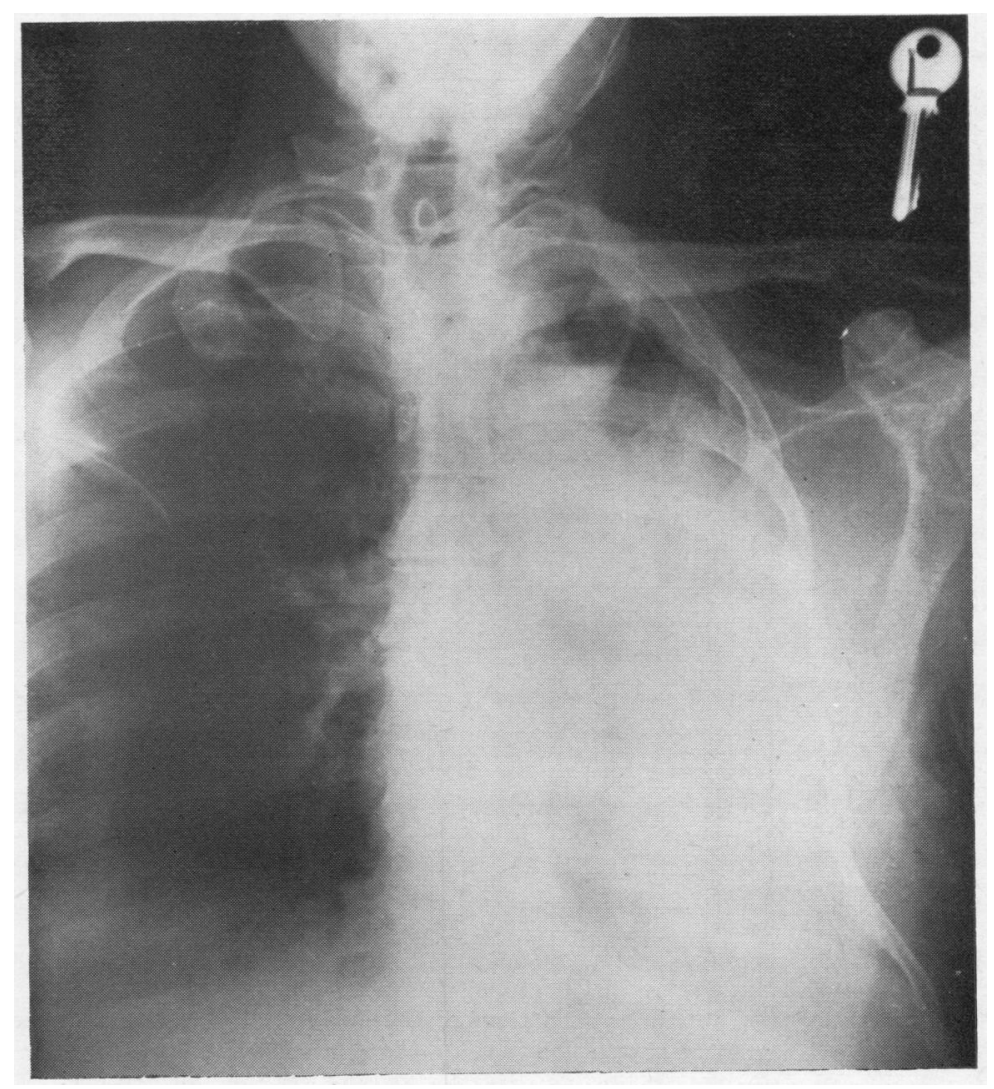


blood pressure and widened mediastinum suggested aortic rupture and this was confirmed by prograde aortogram (the radio-opaque material was injected into the pulmonary artery through a cardiac catheter introduced into the saphenous vein) (Fig. 6). He was transferred to the Regional Thoracic Centre at Broadgreen Hospital for operation.

Operation The chest was opened through the left fourth rib bed posteriorly. The lower lobe was atelectatic but could be expanded after aspirating secretions through the endotracheal tube. The diaphragmatic repair was sound. There was a haematoma in the mediastinum with a fusiform swelling of the aorta $5 \mathrm{~cm}$. below the left subclavian origin. The aorta was dissected above and below the swelling and slings were passed around to permit proximal and distal control. The apex of the left ventricle was exposed on opening the pericardium $2 \mathrm{~cm}$. anterior to the phrenic nerve and a purse string of 00 silk controlled by a snare was inserted. The aorta was $\vec{O}$

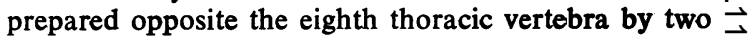
000 opposed purse string sutures. A cannula prepared $\omega$ as described in Case 1 was inserted in the tip of the left ventricle after making a stab wound. There was $\vec{x}$ delay in inserting the distal end into the aorta due o

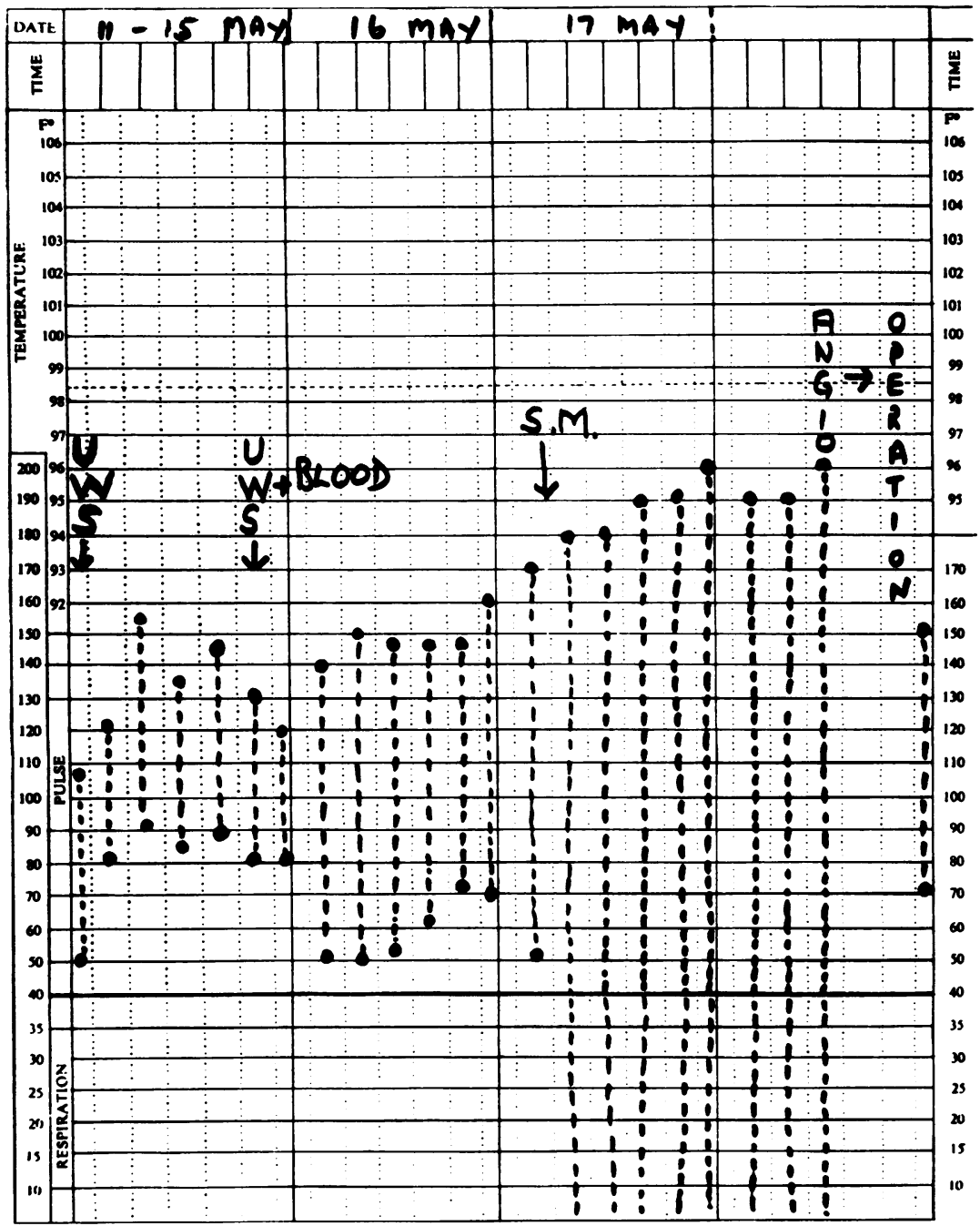

FIG. 8. Case 3. Blood pressure chart showing rise in blood pressure coincident with onset of systolic murmur. UWS = insertion of underwater seal drainage; $S . M .=$ time of onset of systolic murmur; angio= time of aortogram. 


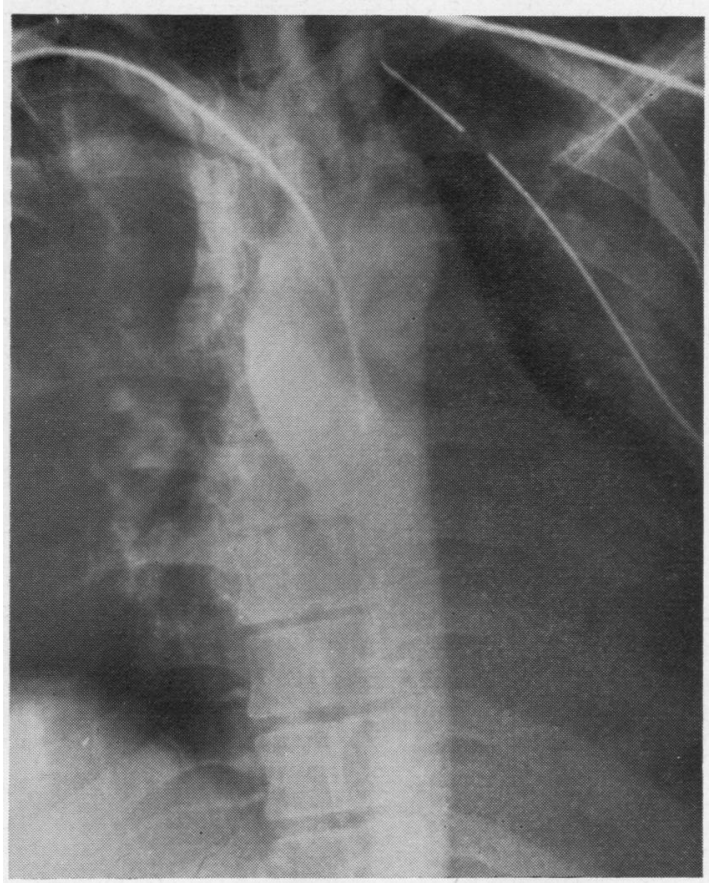

FIG. 9. Case 3. Aortogram, via brachial artery, showing aortic rupture with break in the continuity of the opaque medium. Catheter is in aortic root.

to cardiac dysrrhythmia and in this interval the cannula clotted. It was removed and flushed clean. The patient was heparinized $(3 \mathrm{mg}$. $/ \mathrm{kg}$.) and the cannula was re-inserted into the left ventricle. The distal end was trimmed to a point and placed in the aorta via a vertical incision with the aorta controlled by a Beck clamp. After removing air, the clamps were removed and pulsatile flow could be seen in the cannula. The palpable pressure in the distal segment of the aorta rose. The aorta was clamped above and below the swelling. The heart showed no sign of distension or strain, maintaining an upper body pressure of $120 / 80 \mathrm{~mm}$. $\mathrm{Hg}$ and a lower body pressure nearly the same. The mediastinal pleura was incised to show a spiral tear extending over twothirds the circumference of the aorta. Because of laceration to the intima, it was not thought safe to attempt end-to-end anastomosis and therefore a $2 \cdot 5$ $\mathrm{cm}$. segment of $1 \cdot 6-\mathrm{cm}$. woven Teflon was sutured in to restore continuity. On releasing the clamps there was good flow through the graft and no drop in blood pressure. The cannula was removed from the left ventricle, the incision in which was closed by two 00 sutures. Following this handling, a period of hypotension and dysrrhythmia required adrenaline resuscitation. The aortic end of the cannula was removed and the aorta was closed with a continuous whip stitch of 000 silk. The mediastinal pleura was lightly approximated over the graft after heparin reversal (by protamine sulphate) and the chest was closed with pleural drainage. Post-operative bronchoscopy showed no evidence of bronchial damage.

It was decided to continue ventilation, but to change from D-tubocurarine to control with phenoperidine to assess the cerebral state.

His immediate post-operative course was satisfactory with a stable arterial and venous pressure and good circulation in the extremities. Urine output after provocation with mannitol $\left(100 \mathrm{ml}\right.$. of $12 \frac{1}{2} \%$ i.v.) was good. There was evidence of returning consciousness and appreciation of surroundings. There was no peripheral neurological deficiency.

Thirty-six hours after operation, six days after his initial injury, he became shocked with a falling blood pressure and ultimate cardiac asystole from which he could not be resuscitated. During external cardiac massage it was noted there was blood coming from the pharynx.

Post-mortem examination showed the aortic suture line to be intact and the lumen patent. There were numerous gastric erosions and a 2 by $1 \mathrm{~cm}$. erosion in the first part of the duodenum. There was $200 \mathrm{ml}$. of blood in the stomach. Other injuries included retroperitoneal and perinephric haematomata, haemorrhage into the right adrenal, and traumatic haemorrhage and softening of the inferior part of the right occipital lobe. The cause of death was judged to be acute duodenal haemorrhage.

CASE 3 S. McK., aged 37 years, was thrown from a car in which he was hitch-hiking while intoxicated. On admission to the Royal Victoria Hospital, Belfast, he was unconscious, dyspnoeic, and cyanosed. Haemopneumothorax with fractures of ribs 2 to 7 on the left was diagnosed and an intercostal tube was inserted (Fig. 7). This relieved the dyspnoea and improved the cyanosis. Forty-eight hours later the tube was removed as the thoracic state appeared stable, but 24 hours later he again became dyspnoeic and anxious, although his blood pressure remained stable and raised (Fig. 8). A chest radiograph showed a further haemopneumothorax, and chest aspiration through another intercostal tube produced $450 \mathrm{ml}$. of blood. At this time he developed a high-pitched systolic murmur audible over the back to the left of the upper thoracic spine. His condition appeared stable, but he remained anxious. Palpation of the femoral pulses showed a reduction in tension. By palpation the pressure was $110 / 80 \mathrm{~mm}$. $\mathrm{Hg}$, while the arm pressure was $230 /$ $100 \mathrm{~mm}$. Hg. Re-inspection of the radiographs suggested a widened mediastinum and an aortogram through the brachial artery was performed (Fig. 9). This confirmed the diagnosis. Pressure tracings taken at the time of the aortogram confirmed the disparity in pressures above and below the rupture (Fig. 10). 

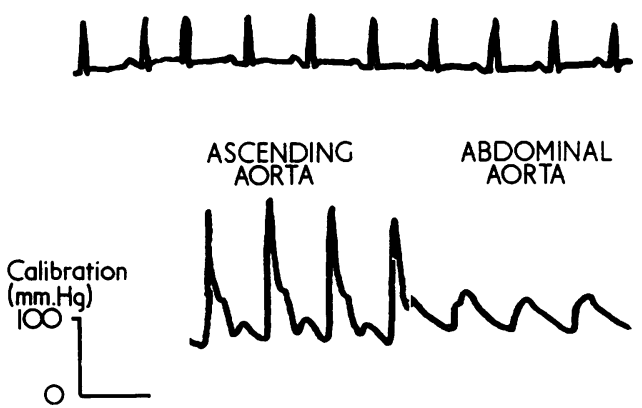

FIG. 10. Case 3. Pressure trace showing disparity between upper and lower aorta pre-operatively.

OPERATION Through a left fifth rib bed incision the chest was opened to show a mediastinal haematoma $2 \mathrm{~cm}$. below the left subclavian artery. Slings were passed above and below the swelling around the aorta. Preparations had been made for left atrioaortic bypass, but on opening the pericardium it was clear there was too diminutive a left atrial appendage to cannulate with safety. Inspection of the atrial wall at the pulmonary vein entry was unpromising as manipulation posteriorly in the pericardium appeared to compromise the aortic haematoma and seemed unsafe. The cannulation technique used for Cases 1 and 2 was employed but heparin was not given. Fine manometer tubes in the femoral artery and the radial artery registered the pressures on an oscilloscope. On clamping the aorta, after removing air from the cannula, flow was observed. Pressure in the radial artery was $120 / 80 \mathrm{~mm}$. $\mathrm{Hg}$, while pressure in the femoral artery, somewhat damped, showed a mean pressure of $60 \mathrm{~mm}$. $\mathrm{Hg}$. The aorta was clamped above and below the haematoma. On incision of the mediastinal pleura a twothirds circumference tear of the aorta was revealed. This was unsuitable for end-to-end anastomosis due to laceration of the intima. After trimming the ends, a $2.5-\mathrm{cm}$. length of $2 \cdot 0-\mathrm{cm}$. woven Teflon was inserted using a continuous suture technique on each end. On releasing the clamps there was good flow through the graft. The bypass, which had functioned satis-

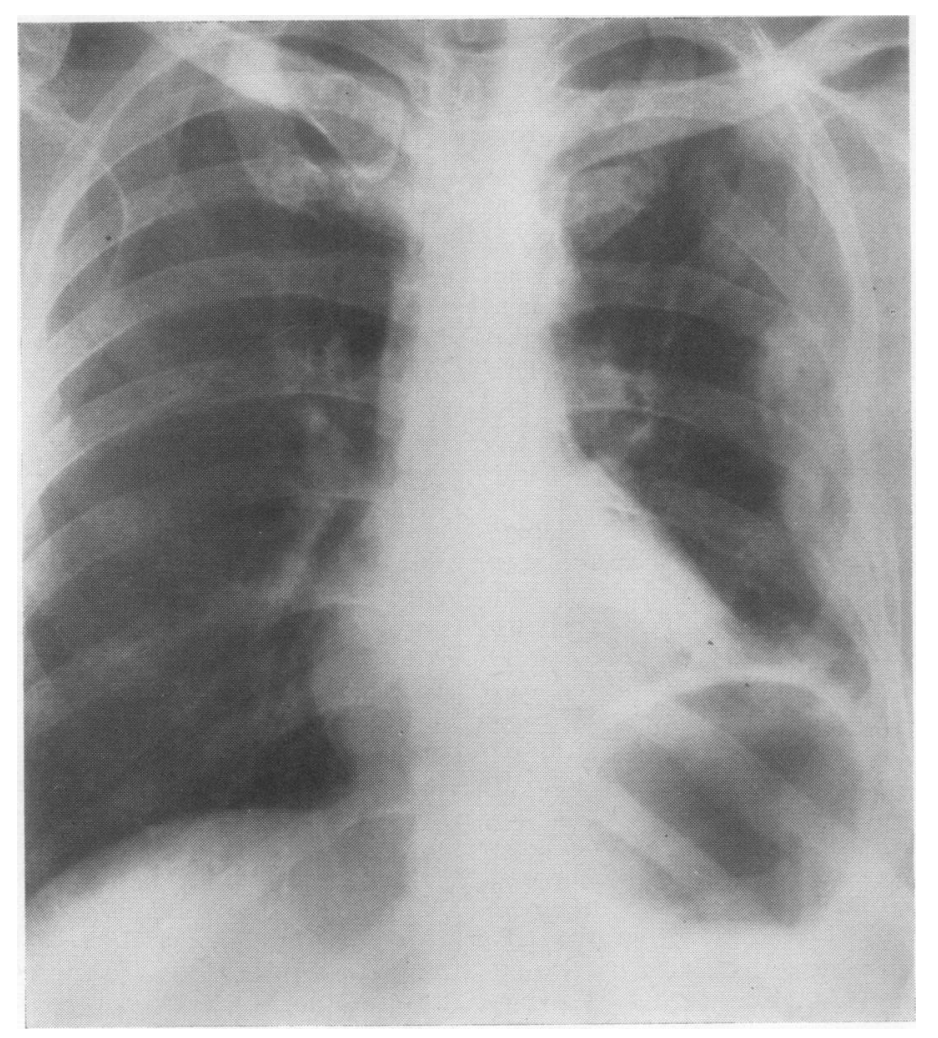

FIG. 11. Case 3. Chest radiograph showing mediastinum of normal width three months post-operatively. The rib fractures remain caved in. 
factorily for $\mathbf{4 0}$ minutes, was dismantled, the ventricular and aortic incisions being closed. The patient had continued to pass urine throughout the procedure and on return to consciousness showed no neurological deficiency. His convalescence was uneventful and he was discharged 20 days later. When seen at out-patients six weeks later, he was well with a normal blood pressure. A radiograph showed clearing of the chest and a return of the mediastinum to normal (Fig. 11). His subsequent progress has been entirely satisfactory.

\section{DISCUSSION}

Many dece'eration injuries result in trauma to the intrathoracic viscera with or without external manifestations. Parmley, Mattingly, Manion, and Jahnke (1958) point out that one-third of patients with major intrathoracic trauma may have no evidence of external injury. Awareness of the possibility of such injury increases the likelihood of early diagnosis and the possibility of restorative surgery. The importance of early diagnosis is emphasized by a review of the literature, which indicates a gloomy prognosis if aortic rupture is undiagnosed. Patients who rupture their aorta usually die immediately. Ten to twenty per cent survive to reach hospital, where the majority succumb within 24 hours. A small group survive to rupture 7 to 10 days later and a smaller group still survive to form aneurysms at the site of the rupture and may remain undiagnosed for many years. Spencer, Guerin, Blake, and Bahnson (1961) report a case who remained unsuspected for 15 years following injury, and Nicks, G. R. (personal communication, 1956) operated on a patient two years after his initial injury (using surface hypothermia). In Spencer's group of 15 patients, 7 were dealt with as acute problems with 5 pre-operative deaths and 1 operative death. One patient developed renal failure and paraplegia with the onset of hypertension. In a series of 172 patients with closed injuries in the chest, Solheim (1963) noted a $45 \%$ overall mortality. The ribs were unfractured in 32 of this group, but 10 of these 32 succumbed to pneumothorax, haemothorax, aortic or diaphragmatic rupture. Of 33 admitted dead, 10 had cardiac or aortic rupture. Of 139 admitted alive, 90 had a haemothorax, of whom 44 perished, 7 with great vessel rupture, 2 being aortic. Spencer et al. (1961) reviewed 43 patients with aortic rupture, of 'whom 34 were due to motor accidents. They related the mechanism of the injury to sudden horizontal deceleration. Thirty-eight of the 43 had the tear at the ligamentum arteriosum region, 2 on the descending aorta and 3 on the ascending aorta. They felt that vertical deceleration would result in aortic valve or proximal aortic rupture. In most cases the tear spirals around the aorta. Slaney, Ashton, and Abrams (1966) reviewed five cases, of whom one survived the acute phase and developed an aortic aneurysm subsequently.

The principal diagnostic points would seem to be the following:

(a) Widening of the mediastinum shown in chest radiograph: It is important to obtain good quality films, as poorly positioned films may obscure this feature. It is equally important in patients with closed chest injuries not to dismiss widening of the mediastinum as arteriosclerotic change, especially in the older patient.

(b) Development of murmurs: This is an uncommon but important sign. Two of the 43 patients reviewed by Spencer et al. (1961) developed a systolic murmur and Case 3 showed this sign clearly.

(c) Dyspnoea and chest pain: These are common to many chest injuries and should direct attention to the thorax and all its contents. In late aneurysm, dyspnoea and hoarseness may appear.

(d) Hypertension: This is an important sign. All the above cases showed a higher blood pressure early in recovery than might be expected. Once the blood pressure exceeds $150 \mathrm{~mm}$. $\mathrm{Hg}$ systolic, aortic compression should be entertained as a diagnostic possibility and radiological aid sought. Laforet (1965) emphasizes this point in early diagnosis, as do Rice and Wittstruck (1951). They noted the occurrence of hypertension between $140 / 100 \mathrm{~mm}$. $\mathrm{Hg}$ and $210 / 120 \mathrm{~mm}$. $\mathrm{Hg}$ in 15 cases. Koroxenidis, Moschos, Landy, Poulos, and Lehan (1965) drew attention to the similarity between aortic rupture and coarctation in the hypertension and delayed femoral pulses. It would seem reasonable if aortic rupture is suspected to take the blood pressure in the legs either by cuff or direct femoral artery puncture. As renal suppression may be present care should be taken not to dismiss the hypertension as arising from a 'Goldblatt' mechanism fol'owing renal ischaemia due to hypovolaemia.

(e) Neurological features: These are not common as there is usually a distal circulation even if reduced. Paraplegia may occur and may be transient if the rupture is repaired, although the prognosis for full neurological return is poor. In the absence of spinal injury, the onset of paraplegia should raise the question of a ruptured aorta. 
$(f)$ Aortography : Since widening of the mediastinum is not solely due to aortic rupture, aortography should be performed. This does not upset the ill patient if expertly carried out and can be either prograde as in Case 2 or through the brachial artery as in Case 3. If the brachial artery is used, the opaque medium should be injected in the ascending aorta (1) to exclude aortic valve or ascending aorta damage; and (2) to obviate the risk of penetrating the haematoma containing the rupture. For this reason the femoral route should be avoided.

MANAGEMENT Once aortic rupture is diagnosed it should be repaired (Keen, Bradbrook, and McGinn, 1969). There is no advantage in delay unless other injuries, particularly head injuries, appear irrecoverable. As emphasized by Braimbridge (1963), protection of the spinal cord, kidneys, and gut is essential. In coarctation, collaterals will support the distal circulation during resection and anastomosis, but in the acute rupture or chronic aneurysm no such protective mechanism exists. Some form of circulatory support is therefore essential. Most authors (Braimbridge, 1963 ; Spencer et al., 1961 ; Gerbode, Braimbridge, Osborn, Hood, and French, 1957 ; DeMuth, Roe, and Hobbie, 1965) have describe 1 either left atrio-femoral or full bypass for support. Nicks, G. R. (personal communication, 1956) employed surface cooling to $32^{\circ} \mathrm{C}$. to resect a chronic aneurysm with success. The major disadvantage of using an extracorporeal circulation is that of heparinization, particularly in the presence of a pulmonary haematoma or other injuries where protracted bleeding, while incoagulable, may make recovery impossible. In centres where extracorporeal circulation is not available, patients with aortic rupture may not receive optimal treatment. Fina!ly, patients with diminutive left atria may make the use of left atrio-femoral bypass unsafe, as in English's case (1965) and Case 3 of the present series.

The concept of left ventriculo-aortic bypass is not new. Sarnoff, Donovan, and Case (1955) described a technique using this for aortic valve stenosis and demonstrated its practicability, although its usefulness for aortic valve disease was not realized. The simplicity, ready availability, and lack of need for heparinization should commend left ventriculo-aortic support to surgeons dealing with severe trauma. The need to dissect the femoral or external iliac arteries for supportive circulation is obviated. This may be precluded by intra-abdominal or upper leg injuries, as in Cases 1 and 2, and makes the utilization of the descending aorta attractive. The cannula lies outside the operative field, is fully in view and pressure monitoring confirms the support of the circulation in the lower half of the body. On releasing the aortic clamps with the left ventriculoaortic perfusion in progress, the usual fall in blood pressure does not occur. As many of these injuries occur to younger patients, the left ventricle, which is strong, can be freely used to support the distal circulation.

The author wishes to thank Dr. E. Epstein for performing the aortogram in Case 2 and $\mathrm{Mr}$. M. Stevenson for referring Case 3.

\section{REFERENCES}

Braimbridge, M. V. (1963). Surgery of the descending thoracic aorta. Ann. roy. Coll. Surg. Engl., 33, 344.

DeMuth, W. E., Jr., Roe, H., and Hobbie, W. (1965). Immediate repair of traumatic rupture of thoracic aorta. Arch. Surg., 91, 602 .

English, T. A. H. (1965). Direct left ventriculofemoral bypass during resection of coarctation of the aorta with anomalous subclavian arteries. Thorax, 20, 36.

Gerbode, F., Braimbridge, M., Osborn, J. J., Hood, M., and French, S. (1957). Traumatic thoracic aneurysms: treatment by resection and grafting with the use of an extracorporeal bypass. Surgery, 42, 975 .

Keen, G., Bradbrook, R. A., and McGinn, F. (1969). Traumatic rupture of the thoracic aorta. Thorax, 24, 25.

Koroxenidis, G. T., Moschos, C. B., Landy, E. D., Poulos, P. P., and Lehan, P. H. (1965). Traumatic rupture of the thoracic aorta simulating coarctation. Amer. J. Cardiol., 16, 605.

Laforet, E. G. (1965). Acute hypertension as a diagnostic clue in traumatic rupture of the thoracic aorta. Amer. J. Surg., 110, 948.

Parmley, L. F., Mattingly, T. W., Manion, W. C., and Jahnke, E. J. (1958). Nonpenetrating traumatic injury of the aorta. Circulation. 17, 1086.

Rice, W. G., and Wittstruck, K. P. (1951). Acute hypertension and delayed traumatic rupture of the aorta. J. Amer. med. Ass. $147,915$.

Sarnoff, S. J., Donovan, T. J., and Case, R. B. (1955). The surgical relief of aortic stenosis by means of apical-aortic valvular anastomosis. Circulation, 11, 564.

Slaney, G., Ashton, F., and Abrams, L. D. (1966). Traumatic rupture of the aorta. Brit. J. Surg., 53, 361.

Solheim, K. (1963). Closed thoracic injuries. Acta chir. scand., 126, 549.

Spencer, F. C., Guerin, P. F., Blake, H. A., and Bahnson, H. T. (1961). A report of 15 patients with traumatic rupture of the thoracic aorta. J. thorac. cardiovasc. Surg., 41, 1. 